\title{
PTEN, a general negative regulator of cyclin D expression
}

\author{
Lirong Diao ${ }^{1}$, Ye-Guang Chen ${ }^{1}$ \\ ${ }^{I}$ State Key Laboratory of Biomembrane and Membrane Biotechnology, Department of Biological Sciences and Biotechnology, Tsing- \\ hua University, Beijing 100084, China
}

Cell Research (2007) 17:291-292. doi:10.1038/cr.2007.24; published online 10 April 2007

The tumor-suppressor phosphatase with tensin homology (PTEN) is frequently mutated in many malignancies and is one of the most well studied tumor suppressor genes $[1,2]$. PTEN, a lipid and protein dual phosphatase, plays a vital role in embryonic development, cell growth, apoptosis and cell migration. The well-known function of PTEN is phosphatidylinositol-3 $\left(\mathrm{PI}_{3}\right)$-phosphatase, which functions as a negative regulator of the $\mathrm{PI}_{3}$ kinase (PI3K) pathway. It is well established that PTEN regulates the G1-S transition by modulating the expression of cyclin D1 and $\mathrm{p} 27^{\mathrm{Kip} 1}$.

The passage of any cell through cell cycles is subtly modulated by a series of proteins, among which the main players in animal cells include cyclins, CDKs (cyclin-dependent kinases, positive regulators) and CDK inhibitors (negative regulators such as $\mathrm{p} 21^{\mathrm{Cip} 1}$ and $\mathrm{p} 27^{\mathrm{Kip} 1}$ ). Cyclin Ds are key regulators during the G1 phase and there are three types of cyclin Ds, D1, D2 and D3 in mammalian cells [3]. Although the phenotypic analyses of single cyclin D knockout mice revealed that each of the D type cyclins is sufficient to drive normal development of the majority of tissues [4], each cyclin D shows distinct and mutually exclusive expression patterns in mouse embryos and some organs of adult animals, indicating individual cyclin D may have their specific functions [5].

It has been documented that cyclin D1 is an important target of PTEN, which downregulates the expression and protein stability of cyclin D1 and inhibits its nuclear localization [6]. PTEN also reduces cyclin D3 levels in endometrial carcinoma cells [7]. Loss of PTEN occurs in a great portion of invasive germ cell tumors [8], while overexpression of cyclin D2 is frequently observed in germ cell tumors [9]. Considering that different cyclin D may

Correspondence:Ye-Guang Chen

Tel: 86-10-62795184; Fax: 86-10-62794376

E-mail:ygchen@tsinghua.edu.cn have distinct functions, it is important to evaluate the effect of PTEN on other cyclin Ds.

In the study reported in Oncogene [10], we provided evidence that cyclin D2 is also an important target of PTEN. We found that the mRNA and protein levels of cyclin D2 were apparently higher in Pten-null cells than those in wild-type mouse embryonic fibroblasts (MEFs), and this elevated expression was suppressed by reintroduction of PTEN. We further defined a pathway involving GSK3 $\beta / \beta$-catenin/TCF in PTEN-mediated suppression of cyclin D2 expression. Treatment of $\mathrm{LiCl}$, an inhibitor of GSK3 $\beta$, abolished the inhibitory effect of PTEN on cyclin D2 expression. TCF members could directly bind to the promoter of cyclin D2 and regulate its transcription in a CREB-dependent manner, indicating a novel mechanism whereby TCF and CREB cooperate in the regulation of cyclin D2 expression. These data also suggest a convergence of the PI3K pathway and Wnt pathway in the modulation of cyclin D2 expression. Significantly, we showed that the greater potential to overcome G1 arrest by loss of PTEN was at least partially contributed by the elevated level of cyclin D2. These findings together suggest that cyclin D2 is an important target of PTEN. Future studies are needed to determine how PTEN influences D2 protein stability and whether the subcellular localization of cyclin D2 is also regulated by PTEN.

\section{References}

1 Di Cristofano A, Pandolfi PP. The multiple roles of PTEN in tumor suppression. Cell 2000; 100:387-390.

2 Cully M, You H, Levine AJ, et al. Beyond PTEN mutations: the PI3K pathway as an integrator of multiple inputs during tumorigenesis. Nat Rev Cancer 2006; 6:184-192.

3 Sherr CJ, Roberts JM. CDK inhibitors: positive and negative regulators of G1-phase progression. Genes Dev 1999; 13:15011512.

4 Ciemerych MA, Kenney AM, Sicinska E, et al. Development 
of mice expressing a single D-type cyclin. Genes Dev 2002; 16:3277-3289.

5 Wianny F, Real FX, Mummery CL, et al. G1-phase regulators, cyclin D1, cyclin D2, and cyclin D3: up-regulation at gastrulation and dynamic expression during neurulation. Dev Dyn 1998; 212:49-62.

6 Radu A, Neubauer V, Akagi T, et al. PTEN induces cell cycle arrest by decreasing the level and nuclear localization of cyclin D1. Mol Cell Biol 2003; 23:6139-6149.

7 Zhu X, Kwon CH, Schlosshauer PW, et al. PTEN induces G(1) cell cycle arrest and decreases cyclin D3 levels in endometrial carcinoma cells. Cancer Res. 2001; 61:4569-4575.

8 Di Vizio D, Cito L, Boccia A, et al. Loss of the tumor suppressor gene PTEN marks the transition from intratubular germ cell neoplasias (ITGCN) to invasive germ cell tumors. Oncogene 2005; 24:1882-1894.

9 Chaganti RS, Houldsworth J. Genetics and biology of adult human male germ cell tumors. Cancer Res 2000; 60:1475-1482.

10 Huang W, Chang HY, Fei T, et al. GSK3 $\beta$ mediates suppression of cyclin D2 expression by tumor suppressor PTEN. Oncogene 9 October 2006; doi:10.1038/sj.onc.1210033 